\title{
Local Resilience Forums in England
}

\author{
By Peter Jones* \& Daphne Comfort ${ }^{\dagger}$
}

\begin{abstract}
The concept of resilience, loosely defined as the ability to withstand or to bounce back from adversity and disruption, is attracting increasing attention within the social sciences. Within the policy arena, local and community based resilience strategies are playing an important part in responses to the challenge of unpredictable and disruptive events. This short exploratory paper looks to add to the literature on community resilience by exploring the work of the Local Resilience Forums in England. The Local Resilience Forums are multi-agency partnerships made up of a range of agencies including the police authority, local authorities, the fire and rescue services, the National Health Service and the Environment Agency, that serve communities defined by the boundaries of police areas. The paper outlines definitions of resilience and of community resilience, provides an exploratory review of the characteristics and workings of the Local Resilience Forums and offers some concluding reflections on the employment of the concept at the community level and by the LRF's.
\end{abstract}

Keywords: Resilience, Local Resilience Forum, Police Authority, Measurement, Governance, England.

\section{Introduction}

Within the social sciences there has been growing interest in the concept of resilience. Andres and Round (2015), for example, identified 'the increasing engagement within the social sciences with notions of resilience' and suggested that the concept 'is becoming influential in state policy.' In exploring 'the governmentalisation of resilience', Welsh (2014) suggested that 'the most obvious adoption of a resilience approach is seen in ways of governing emergency, particularly its national security and emergency response plans where responsibility for preparedness, response and recovery lies in localities, reserving for central government an authoritative, coordinating and facilitating role.' That said, Welsh (2014) also argued that such 'resilience approaches operate on the normative assumption that communities can and should self-organise to deal with uncertainty, that uncertainty is a given, not something with a political dimension, and the role of government is limited to enabling, shaping and supporting, but specifically not to direct or fund those processes.' However, Kapucu and Sadiq (2016) suggested 'there is limited understanding on ways to promote community resilience at the local level.' With these thoughts in mind this, exploratory paper looks to add to the literature on community resilience by exploring the work of the Local Resilience Forums (LRFs) in England. The LRF's are multi-agency partnerships made up of a range of agencies including the police authority, local authorities, the fire and

${ }^{*}$ Professor, The School of Business, University of Gloucestershire, Cheltenham, UK.

${ }^{\dagger}$ Research Associate, The School of Business, University of Gloucestershire, Cheltenham, UK. 
rescue services, the National Health Service and the Environment Agency, that serve communities defined by the boundaries of police areas in England. The paper outlines definitions of resilience and of community resilience, provides an exploratory review of the characteristics and workings of the Local Resilience Forums and offers some concluding reflections on the employment of the concept at the community level and by the LRF's.

\section{Resilience and Community Resilience}

Weichselgartner and Kelman (2015) simply defined the concept of resilience as 'the capacity to cope with change and uncertainty' but several origins and meanings are claimed for resilience. Sharifi and Yamagata (2014), for example. suggested that 'despite the abundance of research on resilience there is still no single, universally accepted definition for it.' Hassler and Kohler (2014) claimed that 'resilience, as a design principle, was an implicit part of construction knowledge before the nineteenth century' and Sharifi and Yamagata (2014) suggested that 'the concept of resilience has traditionally been used in physics and psychology.' Davoudi et al. (2012) acknowledged that 'resilience was first used by physical scientists' and argued that in the 1960's 'resilience entered the field of ecology.' MacKinnon and Derickson (2013) suggested that 'the concept of resilience has migrated from the natural and physical sciences to the social sciences and public policy, as the identification of global threats such as economic crises, climate change and international terrorism, has focused attention on the responsive capacities of places and social systems.' That said, Olsson et al. (2015) have argued that resilience 'is problematic in social science and for understanding society.'

In simple terms, community resilience might typically be defined as 'a measure of the sustained ability of a community to utilize available resources to respond to, withstand, and recover from, adverse situations' (Rand 2018). However, Patel et al. (2017) argued that 'community resilience remains an amorphous concept that is understood and applied differently by different research groups.' Patel et al. (2017) also suggested that 'consensus as to what community resilience is, how it should be defined and what its core characteristics are does not appear to have been reached, with mixed definitions appearing in the scientific literature, policies and practice.' Nevertheless, Wahl (2017) argued 'the community resilience building meme has reached the mainstream agenda.'

Within the UK, two definitions provide an illustration of how local community resilience has been operationalised. The UK's Cabinet Office (2011), for example, defined community resilience as 'communities and individuals harnessing local resources and expertise to help themselves in an emergency, in a way that complements the response of the emergency services.' For the Dorset Local Resilience Forum (2019) community resilience 'is about empowering individuals, businesses and community groups to: take collective action to both increase their own resilience and that of others; come together to identify and support vulnerable 
individuals'; and 'take responsibility for the promotion of individual and business resilience.'

\section{Local Resilience Forums in England}

The formation of LRFs is a requirement of the Civil Contingencies Act 2004 and some 38 LRF's have been established and serve communities geographically defined by the boundaries of Police Areas within England. The LRF's are multiagency partnerships embracing both Category 1 Responders, that are at the core of most emergencies, and Category 2 Responders, that cooperate and share, information with Category 1 Responders, to inform multi-agency planning frameworks.

The major Category 1 Responders are the police authority, the fire and rescue service, the ambulance service, local authorities, National Health Service Trusts, the Environment Agency, and in coastal areas, the maritime authorities. Category 2 providers include the Health and Safety Executive, public utilities companies, transport operators, Highways England and often a range of voluntary groups such as the Red Cross, the Samaritans and the Council for Voluntary Services. The LRF is seen as a 'strategic group' which 'should attract a sufficiently senior level of representation' with the 'local authority representative' being the 'chief executive or deputy chief executive' and 'the police representative' being 'the area chief constable or deputy chief constable' (Cabinet Office 2013).

The 'purpose of the LRF process is to ensure effective delivery of those duties under the Act (i.e. the Civil Contingencies Act 2004) that need to be developed in a multi-agency environment and individually as a Category 1 Responder' (Cabinet Office 2013). More specifically, the Cabinet Office (2013) reported that 'the LRF process should deliver

- The compilation of an agreed risk profile for the area, through a Community Risk Register

- A systematic, planned and co-ordinated approach to encourage Category 1 Responders, to address all aspects of policy in relation to: risk; planning for emergencies; planning for business continuity management; publishing information about risk assessments and plans; arrangements to warn and inform the public; and other aspects of civil protection duty including the promotion of business continuity management by local authorities

- Support for the preparation by some or all of its members of multi-agency plans and other documents, including protocols and agreements and the coordination of multi-agency exercises and other training events.'

The Cabinet Office (2013) emphasised that in order to meet these objectives the LRF needs to operate effectively as a collective body, managing a programme of work and exercising leadership to establish, test and review necessary plans and strategies.' 


\section{Method of Enquiry}

While GOV. UK (2019) has provided a reference document on 'The Role of Local Resilience Forums', which is designed to serve as a 'single reference document that will support Local Resilience Forums (LRFs) by providing a checklist of issues and outcomes that will assist in self assessment, peer review and improvement', the individual LRFs in England provide limited public information on their programmes of work. More specifically, the LRFs are not public bodies and therefore the Freedom of Information Act does not apply to information that they hold. That said, on the one hand the majority of the LRFs provide a short thumbnail sketch of their role and function and provide answers to basic question such as 'What to do in an emergency' and 'How to prepare for an emergency', as well as outline information on the 'Community Risk Register' and 'Weather Advice.' On the other hand, although the Cabinet Office (2013) recommended that 'the LRF will need to engage in deliberate evaluation through meaningful review of functions, procedures and performance in meeting its responsibilities or delivering against its own programme of work and performance outputs', few of the LRC's published any formal information on their constitution, on the economic, social and environmental characteristics of their jurisdiction or on the evaluation of their activities and progress.

With this in mind, the authors harnessed the limited publicly available information to illustrate the characteristics and workings of the LRC's with cameo case studies of the constitution of the Nottingham and Nottinghamshire LRC (2017), the characteristics of the area under the jurisdiction of the Lancashire LRC (2019), the recent annual reports of the County Durham and Darlington LRC (2017) and the South Yorkshire LRC (2018) and a series of interviews conducted across 17 LRFs by Jacobs (2017) on climate change. The authors are aware of the limitations of their approach, not least that it focuses on a small number of LRCs and that it relies exclusively on secondary information. However, they believe that in a field where publicly available information is very limited, their approach offers some insights into the issues the LRCs face, the roles and responsibilities they have adopted and the activities they are undertaking in looking to discharge these roles and responsibilities, that are appropriate for an exploratory study.

\section{Characteristics and Workings of LRCs}

The constitution of the Nottingham and Nottinghamshire LRC's includes information on a number of issues including the enabling legislation; and information on; the membership, structure, strategic goals and operational groups within the LRC; management processes; security vetting policy; information sharing agreement; and the information publication scheme. The strategic goal is 'to establish and maintain effective multi-agency arrangements to respond to major incidents and emergencies, to minimise the impact of those incidents on the public, property and environment of Nottingham and Nottinghamshire, and to satisfy fully the requirements of the Civil Contingencies Act' (Nottingham and Nottinghamshire LRC 2017). Further, the Nottingham and Nottinghamshire LRC 
(2017) emphasised that 'the LRF represents the strategic level of decision making and is responsible for directing and overseeing the emergency planning policies. Its overall purpose is to ensure there is an appropriate level of preparedness to enable an effective multi-agency response to major incidents which may have a significant impact on the communities of Nottingham and Nottinghamshire.'

In looking to address management processes, the constitution of the Nottingham and Nottinghamshire LRF (2017) stressed that its organisational resources must be used in an effective and an efficient manner and that it was thus necessary to prioritise the order in which tasks are addressed and this prioritisation was underpinned by a comprehensive risk assessment process. Here, a Risk Advisory Group, within the LRF, is responsible for the production of the Community Risk Register, which identifies and quantifies hazards, and specifies the arrangements to mitigate and control risks. The Risk Advisory Group also has responsibility for advising the LRF on how to manage risks and, where necessary, for the creation of new plans and for procedures for maintaining and testing existing plans. At the same time, the Resilience Working Group occupies a central position in the LRF management structure in that it formulates the draft business plan, which includes objectives for a number of sub-groups within the LRC, for approval by the LRF, monitors progress against these objectives and reports to the LRF.

Security and the conditions surrounding the sharing of information are major issues for the Nottingham and Nottinghamshire LRF. At a general level, the Nottingham and Nottinghamshire LRF (2017) 'undertakes to adopt the principles of the government security classifications for the marking, transmission, storage, and deletion of documentation.' These principles (GOV. UK 2018) cover the 'secure, timely and efficient sharing of information' and look to ensure that 'everyone who works with government (including staff, contractors and service providers) has a duty of confidentiality and a responsibility to safeguard any Her Majesty's Government information or data that they access, irrespective of whether it is marked or not.' More specifically the constitution covers personal security controls, the purpose and basis of information sharing and the exchange of information, data quality, retention and disposal and access and security.

A brief pen picture offers an insight into how one LRF, the Lancashire Resilience Forum, sees the characteristics of the area under its jurisdiction. The County of Lancashire covers some 3,000 square kilometres, including 123 kilometres of coastline, and has a population of 1.45 million people, and a legacy of industrial heritage. While Lancashire has several urban settlements including Preston, Lancaster, Blackburn, Burnley, Blackpool and Skelmersdale, the county also has sparsely populated coastal, estuarine, agricultural and moorland areas. The major west coast railway and motorway routes run through the entire length of the county and there are ports at Heysham and Fleetwood. The county also houses two nuclear facilities and some of the UK's initial shale fracking sites, which have generated several minor earthquakes, and there are wind power generation facilities and offshore oil fields.

Lancashire LRF (2019) which describes itself as 'a group of organisations that work together to prepare and respond to emergencies in Lancashire' has its 
administrative base at Lancashire Constabulary's Headquarters in Preston. When an incident occurs, all members of the LRF work together to achieve common objectives, namely: to 'prevent the situation from getting worse; save lives; relieve suffering; protect property; recover to normality as soon as possible'; and 'facilitate criminal investigation and judicial processes as necessary.' Lancashire LRF report identifying the following top risks: flu-type pandemics, flooding, terrorist attacks, industrial incidents, loss of essential services, heatwave and storms and gales. In the light of these risks, a variety of impacts and consequences have been identified including the disruption of transport networks, the displacement of people from home or work who may require safe places to shelter, pollution and contamination, large numbers of deaths and/or injuries, disruption to public services and the loss of electricity, gas and water supplies and telephone services.

The LRF maintains a dedicated pandemic plan and in the event of a pandemic responders work together to assess the impact on Lancashire and to support the health authorities and social care system to promote good infection control measures. In a similar vein, the LRF has a group which develops and oversees dedicated flood plans. In the event of a flooding it will alert people to the risk of flooding; assist with managing the evacuation or rescue of people who are at risk; clear drains and roads: put in place safe routes: and after a flood the LRF leads the clear up and recovery operation. The probability of terrorist incidents within Lancashire is perceived to be small, but terrorism is nonetheless a very real threat and while the police force leads all planning in relation to counter terrorism, the LRF works with them to help reduce the risk by supporting the National Counter Terrorism Strategy. The LRF has a dedicated group which looks at hazardous material risks and there is a dedicated plan for each site that is governed by health and safety regulations. Agencies work closely with site operators to test and practice these plans regularly.

In turning to evaluation and reporting, the 2016-2017 Annual Report published by the County Durham and Darlington LRF (2017), looked to provide 'a summary of achievements' and to highlight 'some of the forthcoming challenges.' More specifically, the LRF reported that 'progress against the Business Plan Priorities was excellent with 28 of the Key Deliverables achieved (i.e. 93\%), one not achieved and one partially achieved.' The report provided details of the achievements of each of the LRF subgroups, which included the preparation of community resilience plans; developing plans for managing cyber-attacks; looking to maximise the input of the voluntary sector to achieve more efficient responses and successful recovery; and ensuring that lessons learned in live incidents and training exercises are embedded within operational practice. The LRF also reported that it had been involved in cross-border work in the North East of England, which included work on resilient telecommunications, risk management, and business continuity.

The South Yorkshire LRF (2018) Annual Report 2017-2018 outlined the range of activities it had undertaken, with the focus being on ensuring that South Yorkshire was better prepared to respond to and recover from emergencies. More specifically the report provided details of the work of a number of groups within 
the LRF. The Business Management Group, for example, supports the LRF's strategic objectives and during 2017-2018 led a self-assessment exercise, which led to the development of an action plan designed to enhance the planned response for future emergencies. Following a large-scale exercise to test the tactical response to a terrorism scenario at Meadowhall Regional Shopping Centre in early 2017, the Business Management Group undertook a strategic review exercise to test the LRF's collaborative strategic decision-making capabilities. The LRF's Human Aspects Group, which looks to ensure that appropriate humanitarian arrangements are in place to meet immediate, medium- and long-term needs in the event of an emergency, has collected information to enable it to consider its approach to modern day slavery and a major terrorist attack. This group also worked with the neighbouring Humberside LRF on the new East Coast Tidal Inundation Plan. During 2017-2018 the LRF's Business Continuity Group reported on the business continuity impact of power outages and on identifying and raising awareness of business continuity issues that might affect a range of organisations in South Yorkshire.

-More generally, a series of interviews with members drawn from 17 LRF's across England, conducted in 2017 by Jacobs, as part work for the UK Parliament's Committee for Climate Change: Adaptation Sub Committee, arguably provides some more critical insights into one aspect of the work of the LRF's. While the majority of the interviewees reported that their LRF had sufficient capability to respond to past weather events, many of them suggested there were limiting factors in their ability to respond and that 'they would struggle with larger or more prolonged events' (Jacobs 2017). More generally, some 41\% of the interviewees 'expressed concern about the ability to sustain a prolonged response or recovery, primarily due to perceived reductions in staff numbers and other resources' (Jacobs 2017). While some 30\% of interviewees 'expressed concerns that budget cuts experienced across the agencies have the potential to undermine the emergency response systems', some thought 'staff are now better at coordinating and responding to events and are able to make better use of the resources available' (Jacobs 2017). Some interviewees indicated that the utility companies did not prioritise engagement efforts with LRFs, and there was a general feeling of the 'need to develop stronger connections between LRFs and other stakeholders (both public and private) so that there is a meaningful exchange of information and engagement' (Jacobs 2017).

\section{Discussion}

Within England, the Local Resilience Forums play an important role in responding to a range of disruptive events, including floods, pandemics, terrorist attacks, industrial incidents and loss of essential services. However, the very limited information available in the public realm on the activities of individual LRC's or on their responses to either individual incidents, or types of incident, seriously hampers any attempt to provide a comprehensive exploratory review of 
the general working of the LRCs. and the cameo case studies presented above simply provide some preliminary insights into the activities of the LRCs.

That said, the LRF's do monitor their performance closely and evaluate their responses to specific incidents, and procedures are subject to regular review but outcome of this review process remains confidential to the LRF. This lack of public reporting of the workings of the LRFs is perhaps appropriate, in that security is seen to be paramount. All individuals attending LRF or LRF groups meetings, during an emergency or an exercise, or in receipt of LRF documentation, are expected to have the appropriate level of security clearance for their role, as well as knowledge about the procedures for handling security marked documents. LRF's also have strict protocols governing the sharing of information amongst the responders.

Drawing on the concept of resilience in giving title to the LRF's raises four wider sets of issues, namely: definition; measurement; scale; and governance and political discourse, which merit reflection and discussion. Firstly, there are problems of definition in that, as outlined earlier, resilience has a range of meanings and has been used in a variety of contexts, and as such it can be seen to mean all things to all people and therefore to have little genuine meaning. Davoudi et al. (2012) argued that 'it is not quite clear what resilience means, beyond the simple assumption that it is good to be resilient', and posed the question 'is resilience in danger of becoming just another buzzword?' While Weichselgartner and Kelman (2015) acknowledged that 'the 'elasticity' of the term' and 'the 'flexibility' of the concept' help to explain its popularity, they argued that 'there is an inherent danger that the term becomes an empty signifier that can easily be filled with any meaning to justify any specific goal.' In many ways the LRF's employ the term resilience to describe their work in returning communities and physical infrastructures to their previous state following local emergencies. At same time, while terrorism is a constant threat, the major focus of LRF activity, to date, has been on the impact of natural events, such as floods or pandemics, more so than human events, such as cyberattacks. As such the LRF's collective definition of resilience, and more particularly of community resilience, is relatively narrow and might be seen to be more concerned with how resilience is organised and managed for, communities rather than by, those communities.

Secondly, measuring resilience is a thorny issue and Tanner et al. (2017) argued that 'where the interpretation and definition of resilience is ambiguous, then naturally measurement becomes contested and a major challenge' and that 'the choice of resilience indicators will depend, to some extent, on the system, subsystem or target group that is of interest.' Sharifi (2016) claimed that 'measuring community resilience is recognized as an essential step toward reducing disaster risk and being better prepared to withstand and adapt to a broad array of natural and human disasters.' More specifically in the case of natural disasters in the US, Cutter et al. (2008) argued 'the identification of standards and metrics for measuring disaster resilience is one of the challenges faced by local, state and federal agencies.'

However, the measurement process faces a number of conceptual and methodological challenges. Conceptually, different definitions of resilience do not 
make measurement an easy task and given that resilience is generally seen as being time and place specific, then it is difficult to establish generic measures which facilitate comparisons over time and space. Methodologically, the collection of reliable and meaningful data, particularly in environments and communities, which have suffered shocks, crises and threats, may prove difficult and here organisations and researchers may resort to using available and/or surrogate data rather than looking to collect original data in the field. While the LRF's monitor their responses to disruptive events within communities, the issues of the measurement of the resilience of local communities to such events and the publication of measurement indicators has, to date, received no public attention but may provide a fruitful field of future research endeavour.

Thirdly, there are issues about scale. The disruptive and unpredictable events within communities occur at a range of spatial and temporal scales. The spatial scale refers to the extent of the area affected by a disruptive event while the temporal scale refers to the duration or time length of such an event. The LRF's seem ideally suited to disruptive events and emergencies that occur at a local level, for example, a river bursting its banks and flooding the surrounding residential area or a fire or explosion at a chemical factory which releases toxic fumes into the local atmosphere. Where such events have an impact at a more regional scale, a LRF will work closely with neighbouring LRFs to respond at an appropriate level. However, climate change, often seen to be responsible for a number of disruptive events, including flooding and heatwaves and potentially an increasing prevalence of water borne disease with attendant public health implications, is essentially a global process and here the LRF's can have little or no impact. At the same time, time scale is also important in that the duration of disruptive events may vary considerably and while the impact of a flood or an industrial incident may be temporary, the impact of climate change on the natural environment may be both long term and irreversible.

Finally, there are issues about governance and political discourse, not least in the light of Meerow and Newell's (2016), belief that the 'underlying politics of resilience have been ignored.' In looking to illustrate 'the penetration of resilience discourses and governance' within the UK, Welsh (2014), drew attention to the role of the LRF's in seeking to 'co-ordinate and embed resilience to natural or manmade disaster in all areas of the UK.' For Welsh (2014), 'resilience discourses make a break with the modernism of the risk society by introducing novelty, adaptability, unpredictability, transformation, vulnerability and systems into a governmental discourse that now makes the governance of uncertainty and unpredictability a hallmark of rule.' Further Welsh (2014) looked to 'highlight the potential depoliticising and post-political nature of the resilience discourse as it is mobilised in government structures' and argued that the 'resilience discourse can become defined by a set of consensual socio-scientific knowledges that reduce the political to the policing of change.'

More generally, some critics have argued that popular conceptions of resilience privilege the capitalist mode of production. Amsler (2019) for example, argued that mainstream thinking, learning and policy effectively help societies to 'become resilient within harmful environments that are conceived as inevitable' 
rather than to 'generate possibilities for fundamentally other ways of organizing life.' This reinforces Amsler's (2009) earlier invitation 'to explore the complex processes through which competing visions of just futures are produced, resisted and realized.' More generally, Martin and Sunley (2014) argued that 'the concept of resilience is easily captured by neoliberal ideology, to prioritise the status quo, and the importance of self-reliance, flexibility and the role of self -correcting market adjustments.' Arguably more pointedly, MacKinnon and Derickson (2013) concluded 'resilience thinking has become implicated within the hegemonic modes of thought that support global capitalism.'

\section{References}

Amsler, S. S. (2009), Embracing the Politics of Ambiguity: Towards a Normative Theory of Sustainability. Capitalism, Nature and Socialism 20 (2): 111-125.

Amsler, S. S. (2019) Gesturing towards radical futurity in education for alternative futures. Sustainability Science 14 (4): 925-930

Andres, L. and Round, J. (2015) The role of persistent resilience with everyday life and polity: households coping with marginality within the Big Society. Environment and Planning A, 47 (3): 676-690

Cabinet Office (2011) Strategic National Framework on Community Resilience. Retrieved from https://m.oxfordshire.gov.uk/cms/sites/default/files/folders/documents/fireand publicsafety/emergency/StrategicNationalFramework.pdf [Accessed 19 August 2019]

Cabinet Office (2013) The role of Local Resilience forums: A reference document. Retrieved from https://assets.publishing.service.gov.uk/government/ uploads/system/ uploads/attachment_data/file/62277/The_role_of_Local_Resilience_Forums-_A_refe rence_document_v2_July_2013.pdf [Accessed 19 August 2019]

County Durham and Darlington Local Resilience Forum (2017) Annual Report 20162017. Retrieved from https://www.durham.police.uk/Documents/County\%20Durha m\%20and\%20Darlington\%20LRF\%20Annual\%20Report\%202016-17\%20FINA L. docx.pdf [Accessed 19 August 2019]

Cutter, S.L., Barnes, L., Berry, M., Button, C., Evans, E., Tae, E. and Webb, J. (2008) A place-based model for understanding community resilience to natural disasters.

Global Environmental Change 18: 598-606

Davoudi, S., Shaw, K., Haider, L.J., Quinlan, A. E., Peterson, G. D., Wilkinson, C., Funfgeld, H., McEvoy, D., and Porter, L. (2012) Resilience: A Bridging Concept or a

Dead End? Reframing Resilience: challenges for Planning Theory and Practice Interacting Traps: Resilience Assessment of a Pasture Management System in Norther Afghanistan Urban Resilience: What does it mean in Planning Practice? Resilience as a Useful Concept for Climate Change Adaptation? The Politics of Resilience in Planning: A Cautionary Note. Planning Theory and Practice 13 (2) 299-233

Dorset Local Resilience Forum (2019) Community Involvement. Retrieved from https:// www.dorsetprepared.org.uk/community-involvement/ [Accessed 19 August 2019]

GOV. UK. (2018) 'Government Security Classifications', Retrieved from https://www. gov.uk/government/publications/government-security-classifications [Accessed 31 December 2019]

Hassler, U. and Kohler, N. (2014) Resilience in the Built Environment. Building Research and Information 42 (20): 119-129 
Jacobs (2017) Local Resilience Forum 2017 Interviews. Retrieved from file://C:/Users/A sua/AppData/Local/Packages/Microsoft.MicrosoftEdge_8wekyb3d8bbwe/TempState /Downloads/Local-Resilience-Forum-Interviews-Report-2017-Jacobs-1.pdf [Accessed 19 August 2019]

Kapucu, N. and Sadiq, A-A. (2016) Disaster Policies and Governance: Promoting Community Resilience. Politics and Governance 4 (4): 58-61

Lancashire Local Resilience Forum (2019) Preparing for Emergencies in Lancashire. Retrieved from 'file:///C:/Users/Asua/AppData/Local/Packages/Microsoft.Microsoft Edge_8wekyb3d8bbwe/TempState/Downloads/Preparing-For-Emergencies-Booklet \%20(3).pdf [Accessed 20 August 2019]

MacKinnon, D and Derickson, K.D. (2013) From Resilience to Resourcefulness: A critique of Resilience Policy and Activism. Progress in Human Geography 37 (20): 253-270

Martin, R. and Sunley, P. (2014) On the Notion of Regional Economic Resilience; Conceptualisation and Explanation. Economic Geography 15 (1): 1-19

Meerow, S. and Newell, J.P. (2016) Urban resilience for who, what, when, where and why? Urban Geography, Retrieved from http://www.tandfonline.com/doi/full/10.10 80/02723638.2016.1206395\#.V4UeoPkrKUk [Accessed 27 September 2017]

Nottingham and Nottinghamshire LRF (20017) LRF Constitution. Retrieved from file:/// C:/Users/Asua/AppData/Local/Temp/LRF_constitution_March_2017-5.pdf [Accessed 29 December 2019]

Olsson, L., Jerneck, A., Thoren, H., Persson, J. and O'Byrne, D. (2015) Why resilience is unappealing to social science: Theoretical and empirical investigations of the scientific use of resilience. Sciences Advances 1 (4), Retrieved from https://advan ces.sciencemag.org/content/1/4/e1400217 [Accessed 20 September 2019]

Patel, SS. Brooke-Rogers, M, Amlot. R. and James-Rubin, G. (2017) What Do We Mean by 'Community Resilience'? A Systematic Literature Review of How It Is Defined in the Literature. Retrieved from http://currents.plos.org/disasters/article/what-dowemean-by-community-resilience-a-systematic-literature-review-of-how-it-isdefinedin-theliterature/?utm_content=buffer66cd $1 \& u t m \_m e d i u m=s o c i a l \& u t m \_s o u r c e=t w i$ tter.com\&utm_campaign=buffer [Accessed 19 August 2019]

Rand (2018) Community Resilience. Retrieved from https://www.rand.org/topics/commu nity-resilience.html [Accessed 18 August 2019]

Sharifi, A. (2016) A critical review of selected tools for assessing community resilience. Ecological Indicators 69: 629-647

Sharifi, A. and Yamagata, Y. (2014) A conceptual framework for assessment of urban energy resilience. Retrieved from https://ac.els-cdn.com/S1876610215013545/1-s2. 0-S1876610215013545-main.pdf?_tid=e294fa1a-ad91-11e7-9e9d-00000aab0f27\&a cdnat=1507622954_14c75dc4e7de0b430742e991f1fd3fff [Accessed 27 September 2017]

South Yorkshire Local Resilience Forum (2018) Annual Report 2017/2018. Retrieved from file:///C:/Users/Asua/AppData/Local/Packages/Microsoft.MicrosoftEdge_8w ekyb3d8bbwe/TempState/Downloads/SYLRF_Annual_Report_2017_18\%20(1).pdf [Accessed 19 August 2019]

Tanner, T., Badahur, H. and Moench. M. (2017) Challenges for Resilience Policy and Practice. Retrieved from https://www.odi.org/sites/odi.org.uk/files/resource-docume nts/11733.pdf [Accessed 21 August 2109] 
Wahl, R. (2017) Local and regional community resilience building is going global. Retrieved from https://medium.com/age-of-awareness/local-and-regional-commu nity-resilience-building-is-going-global-bf8b3dce93a4 [Accessed 17 August 2019]

Weichselgartner, J. and Kelman, I (2015) Geographies of resilience: Challenges and opportunities of a descriptive concept. Progress in Human Geography 39 (3): 249267

Welsh, M. (2014) Resilience and responsibility: governing uncertainty in a complex world. The Geographical Journal 180 (1): 15-26 